\title{
Pengaruh Food Quality dan Kesesuaian Harga Terhadap Kepuasan Konsumen (Studi Kasus: Gaembull Korean and Japanese Restaurant Barbeque All You Can Eat Cabang Bintaro)
}

\section{The Influence of Food Quality and Price Towards Consumer Satisfaction (Case Study: Gaembull Korean and Japanese Restaurant Barbeque All You Can Eat Bintaro Branch)}

\author{
Regina Dewi Hanifah ${ }^{1)}$ \\ 1) Program Studi Perhotelan, AKPAR Bunda Mulia
}

27 Desember 2019

\begin{abstract}
The increase in culinary business in the last few years has become a reinforcement for entrepreneurs in the food and beverage sector. It also forces culinary entrepreneurs to be more creative in offering their main products to compete with other culinary businesses. One of them is the increasing number of restaurants that offer a buffet style concept or commonly known by our society as "All You Can Eat" Restaurant. To be able to differentiate itself from competitors, Gaembull Restaurant chose the Korean and Japanese Barbeque themes to be served to its customers at quite affordable prices with quite a large number of types of food. Of course, with this offer many consumers are interested in this, sometimes consumers must be willing to wait to eat at this restaurant. The purpose of this study is to be able to see The Influence of Food Quality and Price towards Consumer Satisfaction. By using multiple regression analysis methods, $\mathrm{f}$ test, $\mathrm{t}$ test and looking for the coefficient of determination, the respondents used were 100 consumers of Gaembull Bintaro Branch Restaurant. The results found from this study are the absence of the influence of Food Quality and Price Conformity both simultaneously and partially on Consumer Satisfaction in Gaembull Restaurant.
\end{abstract}

Keywords: Food Quality, Price Match, Consumer Satisfaction, All You Can Eat Restaurants

\begin{abstract}
ABSTRAK
Peningkatan dalam bisnis kuliner beberapa tahun terakhir menjadi penguat bagi para pengusaha di bidang makanan dan minuman. Hal ini juga memaksa para pengusaha kuliner untuk semakin kreatif dalam menawarkan produk andalannya agar bisa terus bersaing den gan bisnis kuliner lainnya. Salah satunya adalah meningkatnya jumlah restoran yang menawarkan konsep buffet style atau biasa dikenal oleh masyarakat kita sebagai “All You Can Eat" Restaurant. Untuk dapat membedakan dirinya dengan pesaing, Gaembull Restoran memilih tema Korean dan Japanese Barbeque untuk disajikan kepada para pelanggannya dengan harga yang cukup terjangkau dengan jumlah tipe makanan yang cukup banyak. Tentunya dengan penawaran ini banyak konsumen yang tertarik akan hal ini, sehingga seringkali konsumen harus rela menunggu untuk makan di restoran ini. Tujuan dari penelitian ini adalah untuk dapat melihat pengaruh dari Food Quality dan Kesesuaian Harga Terhadap Kepuasan Konsumen. Dengan menggunakan metode analisis regresi berganda, uji f, uji t dan mencari koefisien determinasi, responden yang digunakan adalah 100 orang konsumen Gaembull Restoran Cabang Bintaro. Hasil yang ditemukan dari penelitian ini adalah tidak adanya pengaruh Food Quality dan Kesesuaian Harga baik secara simultan maupun partial terhadap Kepuasan Konsumen di Gaembull Restoran.
\end{abstract}

Keywords: Kualitas Makanan, Kesesuaian Harga, Kepuasan Konsumen, Restoran All You Can Eat 


\section{PENDAHULUAN}

Bisnis kuliner dalam beberapa tahun terakhir sudah semakin menjamur diberbagai belahan Indonesia khususnya di kota-kota besar seperti di Jakarta, Bogor, Tangerang dan juga Depok. Industri makanan yang sudah bergerak sejak abad ke-17 ini diminati banyak kalangan. Hal ini terjadi karena bisnis kuliner memiliki peluang yang sangat besar untuk bersaing dalam pasar selain itu bisnis kuliner memiliki peluang besar dikarenakan manusia tidak lepas dari kebutuhan primernya yaitu pangan atau makan. Pertumbuhan industri makanan dan minuman mulai menjadi andalan sebagai penopang pertumbuhan ekonomi nasional dan manufaktur. Pada 2019 sektor makanan dan minuman diyakini terus menjadi primadona, terutama pada sektor industri pariwisata yang mengembangkan wisata kuliner.

CNN Indonesia (Juniman, 2017) menyatakan sektor kuliner Indonesia tumbuh rata-rata $14 \%$ per tahun dalam lima tahun terakhir hingga saat ini. Didukung oleh pernyataan yang dikeluarkan oleh Badan Pusat Statistik (BPS), dimana pertumbuan industri makanan dan minuman pada triwulan I 2019 mencapai $6,77 \%$, triwulan II $7,99 \%$, dan triwulan III $8,33 \%$. Secara tahun kalender, pertumbuhan industri makanan dan minuman sebesar 7,72\%. Peningkatan ini menunjukan semakin banyak pengusaha kuliner maka semakin banyak juga kompetitor yang harus di hadapi. Para pengusaha kuliner berusaha untuk semakin kreatif dalam menawarkan produk andalannya agar bisa terus bersaing dengan bisnis kuliner lainnya. Meski begitu mereka juga tetap harus mempertahankan konsep dan produk yang mereka miliki. Dalam bisnis kuliner terdapat berbagai macam jenis seperti Coffee Shop, Fast Food, Fine Dining Restoran, Bakery, dan Patisserie dengan tipe-tipe pelayanan yang bermacam-macam, seperti American Service (Plate Service), Russian Service (Platter Service), French Service (Gueridon Service), English Service (Family Service) dan Buffet (Prasmanan). Dimanatren untuk kuliner saat ini adalah Restoran dengan tema "All You Can Eat" yang mengusung tema pelayanan Buffet, yaitu konsumen diperkenankan untuk mengambil dan memilih makanan sendiri yang telah diatur diatas meja buffet. Belakangan ini restoran dengan tema "All You Can Eat" meningkat dengan tajam dikarenakan perilaku konsumen yang mulai berubah. Kontribusi perilaku konsumenyang lebih memilih restoran dengan tema "All You Can Eat" didukung oleh generasi millennial dimana kebiasaan makan di luar rumah dan berkumpul bersama teman maupun keluarga menjadi salah satu factor pemicunya. Selain itu konsumen saat ini merubah kebiasaannya sebagai "Value Seeker" dimana para konsumen mencari keuntungan dari kehadiran promo, khususnya Promo Digital.

Sebagai salah satu kawasan yang berkembang, Bintaro merupakan daerah hunian yang bersebelahan dengan Jakarta Selatan didominasi oleh banyaknya generasi Millenial juga masyarakat dengan tingkat ekonomi menengah keatas. Untuk kawasan Bintaro, Tangerang Selatan, sudah tidak asing lagi restoran bertemakan "All You Can Eat" hadir memenuhi keinginan para pecinta makanan di daerah tersebut. Dikarenakan memang tingginya biaya hidup di kawasan tersebut, berdampak juga dengan harga makanan yang muncul dan memberikan harga tidak terlalu murah sebelumnya karena mengikuti standar hidup para konsumen di daerah tersebut. Restoran tersebut juga menyasar market segment yang sedang berbelanja, sehingga banyak ditemukan di dalam pusat perbelanjaan. Sebutlah seperti Hanamasa, Kintan, Shaburi dan juga Sizzler pada masa sebelum "All You Can Eat" dengan harga yang lebih murah hadir. Nama-nama Restoran tersebut sangatlah merebak dan dapat merajai pangsa pasar pecinta makanan untuk dapat mengambil sepuasnya di daerah tersebut. Kini, Restoran tersebut sudah memiliki banyak pesaing, khususnya dari jumlah harga yang berbeda sangat jauh dibandingkan dengan kedua Restoran ternama diatas. Berdasarkan https://pergikuliner.com/ sebuah platform yang digunakan dalam mencari referensi untuk mencari sebuah tempat makan di suatu daerah, berikut 9 tempat rekomendasi Restoran "All You Can Eat" yang berada di kawasan Bintaro: Hanamasa, Shaburi \& Kintan Buffet, Ngunya, Shabu Hachi, Grill 99, Gaembull, Manse Korean Grill, Pochajjang Korean BBQ, dan juga Sushi Enju. Berbeda dengan Hanamasa juga Shaburi dan Kintan Buffet, 7 restoran lainnya mengusung tema "All You Can Eat" dengan harga terjangkau dan dengan tema yang berbeda-beda. Salah satunya sebagai pendatang 
baru di dunia restoran "All You Can Eat" adalah Gaembull.

Gaembull sendiri merupakan salah satu kategori restoran dengan tema "All You Can Eat" dengan mengusung konsep self service dengan harga yang terjangkau dengan tema Korean dan Japanese Barbeque. Adapun restoran ini telah memiliki 4 cabang restoran yang tesebar di daerah Tangerang dan juga Jakarta. Berikut merupakan tempat outlet dari Gaembull Korean and Japanese Restaurant Barbeque All You Can Eat: Bintaro 2 Outlet, Serpong, Bekasi, Bandung, Makassar, Greenville, Cikupa, dan juga Greenlake. Gaembull memberikan harga Rp. 85.000++ untuk makan siang dan Rp. 95.000++ untuk makan malam. Di Gaembull tersedia 5 varian daging sapi yang tersedia disini seperti Original Beef, Bulgogi Beef, Japanese Marinated Beef, Garlic Chicken, Chicken Sausage, serta menu tambahan Yakikawa (kulit ayam), Toppoki dan condiment lainnya yang ditawarkan bagi para konsumennya. Selain daging, tersedia berbagai menu siap santap seperti karage, japchae, dan pajeon. Daging-daging premium dimarinasi sehingga sangat lembut dan mudah dikunyah sehabis dipanggang sebentar di atas kompor yang tersedia di meja konsumen. Untuk saus pendamping daging, restoran ini menawarkan beberapa rasa seperti Original Sauce, Japanese Sauce, Spicy Dressing dan Gochujang. Gaembull muncul di kawasan Bintaro dengan harga yang cukup terjangkau dan memiliki tipe yang berbeda dengan restoran "All You Can Eat" di kawasan Bintaro, yaitu bukan di pusat perbelanjaan tetapi di sekitar daerah perumahan dan tempat usaha di lokasi yang sangat strategis yaitu di pinggir jalan raya utama di kawasan Bintaro. Gaembull juga menjadi primadona baru dimana konsumen selalu memenuhi restoran ini pada jam makan dan terkadang konsumen diharuskan menunggu untuk dapat menikmati layanan di restoran ini.

Berdasarkan penelitian sebelumnya Wei (2003), banyak faktor yang mendukung seseorang untuk memilih makan di restoran "All You Can Eat", dimana nilai tertinggi didapat dari Harga yang ditawarkan, variasi makanan dan layanan yang ditawarkan. Berkaitan dengan industri restoran, total layanan makanan mencakup komponen berwujud dan tidak berwujud. Berkenaan dengan komponen berwujud, ini adalah saat ketika kualitas makanan telah mengambil peran penting dalam mempertahankan bisnis restoran. Kualitas makanan telah dianggap sebagai elemen mendasar dari pengalaman makan pelanggan yang mempengaruhi kepuasan pelanggan dan menentukan perilaku masa depan (Mayounga, 2018). Menurut Mayounga (2018), Kualitas makanan adalah karakteristik kualitas makanan yang dapat diterima oleh konsumen. Kualitas makanan adalah persyaratan produksi makanan yang penting, karena konsumen makanan rentan terhadap segala bentuk kontaminasi yang mungkin terjadi selama pembuatan proses. Banyak konsumen juga bergantung pada standar pembuatan dan pemrosesan, terutama untuk mengetahui bahan apa yang ada, persyaratan gizi, atau kondisi medis (seperti Diabetes, atau alergi). Kualitas makanan adalah salah satu cara terbaik untuk memaksimalkan kesuksesan dalam bisnis restoran. Terlepas dari pentingnya kualitas makanan dalam bisnis restoran, tantangan penting yang dihadapi industri restoran akhir-akhir ini adalah menawarkan makanan berkualitas yang tidak hanya menarik bagi pelanggan tetapi juga dapat lebih baik bagi pesaing bisnis. Makanan adalah produk yang sangat penting untuk restoran karena makanan adalah produkyang dijual oleh restoran dan akan menghasilkan pendapatan yang menguntungkan. Sangat penting untuk menjaga kualitas makanan untuk restoran karena kualitas makananjuga mewakili kualitas restoran di mata para tamu. Warisan dan Harianto (2018), mendukung bahwa adanya beberapa factor yang mempengaruhi konsumen dalam memilih restoran "All You Can Eat" khususnya di Surabaya. Adapun faktor-faktor yang mempengaruhinya adalah sebagai berikut: harga, kualitas layanan, kualitas makanan, atmosfer restoran dan lokasi. Sedangkan variable paling dominan untuk konsumen adalah harga yang mempengaruhi konsumen untuk memilih restoran “All You Can Eat”. Hal ini menjadi landasan bagi Penulis untuk mendukung fenomena banyaknya konsumen yang memilih Gaembull All You Can Eat Korean and Japanese Barbeque Restaurant saat periode makan siang maupun malam yang rela mengantri untuk mendapatkan layanan dari restoran tersebut, dimana dalam penelitian ini Penulis fokus terhadap Food Quality dan Harga yang ditawarkan oleh Gaembull sesuai dengan promosi yang mereka tawarkan yaitu "Makan 
Daging Sepuasnya Seperti di Restoran Mewah".

\section{TUJUAN PENELITIAN}

Tujuan dari penelitian ini adalah untuk mengetahui apakah Food Quality dan Kesesuaian Harga yang dimiliki oleh Gaembull Restoran Bintaro Sektor 7 memiliki pengaruh secara signifikan baik secara partial maupun simultan terhadap Kepuasan Konsumennya. Sehingga nantinya dapat menjadi masukan bagi pihak manajemen restoran dalam mengambil keputusan mengenai Food Quality dan Harga yang sudah dimiliki.

\section{TINJAUAN PUSTAKA}

\section{A. Food Quality}

Kualitas merupakan kebutuhan dari setiap individu atau setiap orang dalam melakukan keputusan belinya. Kualitas makanan adalah karakteristik kualitas dari makanan yang dapat diterima oleh konsumen. Ini termasuk dalam faktor eksternal seperti ukuran, bentuk, wama, konsistensi, tekstur, dan rasa. Standar kualitas makanan meskipun sulit untuk didefinisikan dan tidak dapat diukur secara mekanik, masih dapat dievaluasi lewat nilai nutrisinya, tingkat bahan yang digunakan, rasa dan penampilan dari produk. Meskipun ada perbedaan pendapat mengenai pengaplikasian kriteria-kriteria tersebut pada setiap makanan. Beberapa faktor yang mempengaruhi pendapat masing-masing orang tentang kriteria tersebut antara lain usia, latar belakang budaya dan sosial, ekonomi, pengalaman masa lalu yang berkaitan dengan makanan, pendidikan dan pengetahuan ilmiah serta emosi (Widjaja, 2006). Kualitas makanan akan berpengaruh pada kepuasan konsumen untuk itu restorant atau penjual makanan diharapkan kualitas makanan menjadi strategi pemasarannya.

Hanaysha (2016) mengklasifikasikan beberapa elemen dari food quality yang dapat mempengaruhi kualitas makanan adalah sebagai berikut:

1. Presentation of food: Makanan harus baik dilihat saat berada di piring, di mana hal tersebut adalah suatu faktor yang penting. Bagaimana makanan tersebut terlihat menarik pada saat disajikan di atas piring.
2. Taste: Kualitas dalam hal rasa dan cita rasa berbeda yang dijaga dengan baik sesuai cita rasa yang diinginkan konsumen.

3. Diversity of choice: Variasi menu yang ditawarkan seperti variasi jenis makanan dan variasi jenis minuman yang beraneka ragam.Variasi makanan dan minuman menjadi salah satu point penting dalam penilaian konsumen dalam kualitas makanan.

4. Healthy: Kualitas dalam hal kesehatan makanan pada saat dikonsumsi oleh konsumen, seperti gizi yang terdapat didalam makanan yang disajikan.

5. Freshness: Kualitas dalam hal kesegaran dari bahan makanan yang diolah adalah contoh penting yang akan mempengaruhi penampilan makanan baik atau tidak untuk dinikmati.

6. Temperature: Kesesuaian variasi temperature yang didapatkan dari makanan dan minuman yang satu dengan lainnya. Temperature juga bisa mempengaruhi rasa, misalnya rasa manis pada sebuah makanan akan lebih terasa saat makanan tersebut masih hangat, sementara rasa asin pada sup akan kurang terasa pada saat sup masih panas.

\section{B. Harga}

Menurut Kotler dan Armstrong (2008), harga adalah sejumlah uang yang ditagihkan atas suatu produk atau jasa, atau jumlah nilai yang ditukarkan para pelanggan untuk memperoleh manfaat dari memiliki atau menggunakan suatu produk atau jasa. Ezel dalam Sunyoto (2013), harga adalah nilai yang disebutkan dalam mata uang atau medium moneter lainnya sebagai alat tukar. Karena jika penetapan harga produk terlalu mahal, tidak sesuai dengan kualitasnya, konsumen akan cenderung meninggalkannya dan mencari produk sejenis lainnya. Sebaliknya, jika penetapan harga produk terlalu murah, konsumen ada kemungkinan akan membeli dalam jumlah relative banyak. Berdasarkan pernyataan tersebut dapat disimpulkan bahwa Kesesuaian Harga adalah kesesuaian sejumlah uang yang dibayarkan konsumen dengan kualitas barang/jasa yang didapatkan. Penetapan harga produk terlalu mahal, tidak sesuai kualitasnya, konsumen akan meninggalkannya dan mencari produk sejenis lainnya dan penetapan harga produk terlalu murah, konsumen ada kemungkinan akan membeli dalam jumlah relative banyak. Menurut Kotler dan Amstrong (2008), 
indikator yang digunakan untuk mengukur harga antara lain:

1. Keterjangkauan harga

2. Kesesuaian harga dengan kualitas produk

3. Daya saing harga

4. Kesesuaian harga dengan manfaat produksi

5. Harga mempengaruhi daya beli konsumen

\section{Kepuasan Konsumen}

Kepuasan Konsumen adalah tingkat perasaan konsumen setelah membandingkan antara apa yang diterima dan harapannya seperti yang dijabarkan oleh Umar (2005). Seorang konsumen, jika merasa puas dengan nilai yang diberikan oleh produk atau jasa, sangat besar kemungkinannya menjadi pelanggan dalam waktu yang lama. Ketika konsumen merasa puas akan jasa yang ditawarkan maka perusahaan akan memperoleh tanggapan dan umpan balik secara langsung dari pelanggan dan juga memberi tanda (signal) positif bahwa perusahaan menaruh perhatian terhadap para pelanggannya.

Hawkins dan Lonney dikutip dalam Tjiptono (2004) indikator pembentuk kepuasan konsumen terdiri dari :

\section{Kesesuaian Harapan}

Merupakan tingkat kesesuaian antara kinerja jasa yang diharapkan oleh konsumen dengan yang dirasakan oleh konsumen

\section{Minat Berkunjung Kembali}

Merupakan kesediaan konsumen untuk berkunjung kembali atau melakukan pemakaian ulang terhadap jasa terkait

\section{Kesediaan Merekomendasi}

Merupakan kesediaan konsumen untuk merekomendasikan jasa yang telah dirasakan kepada teman atau keluarga.

\section{METODE PENELITIAN}

\section{A. Jenis Penelitian}

Metode yang digunakan dalam penelitian ini yaitu bersifat deskriptif dengan pendekatan kuantitatif. Berdasarkan Sugiyono (2017) Metode penelitian deskriptif adalah penelitian yang dilakukan untuk mengetahui keberadaan variabel mandiri, baik hanya pada satu variabel atau lebih (variabel yang berdiri sendiri atau variabel bebas) tanpa membuat perbandingan variabel itu sendiri dan mencari hubungan dengan variabel lain. Sedangkan penelitian kuantitatif diartikan sebagai metode penelitian yang berlandaskan pada filsafat positivisme, digunakan untuk meneliti pada populasi atau sampel tertentu, pengumpulan data menggunakan instrumen penelitian, analisis data yang bersifat kuantitatif atau statistik, dengan tujuan untuk menguji hipotesis yang telah ditetapkan. Dalam penelitian ini data yang digunakan oleh Penulis adalah data primer dan data sekunder. Menurut Sugiyono (2017), data primer adalah data yang diperoleh langsung dari sumber pertama yaitu dari responden. Sedangkan data sekunder adalah data primer yang telah diolah lebih lanjut oleh pihak lain yang dapat berupa catatan, tabel, diagram dan grafik yang menjelaskan suatu permasalahan yang terkait dengan masalah yang diteliti. Data tersebut diatas dapat diperoleh dengan cara observasi dan penyebaran kuesioner.

\section{B. Populasi dan Sampel}

Populasi dalam penelitian ini adalah konsumen dari Gaembull All You Can Eat Korean and Japanese Barbeque Restaurant khususnya di cabang Bintaro Sektor 7. Mengacu pada pernyataan dari Hair dkk dalam Prawira (2010) bahwa jumlah sampel sebagai responden adalah 5 kali dari jumlah pertanyaan yang terdapat dalam kuisioner. Indikator dalam penelitian ini terdiri dari. Total pertanyaan dalam penelitian ini adalah 20 pertanyaan sehingga minimal ukuran sampel penelitian ini adalah $20 \times 5=$ 100 responden.

\section{Metode Analisis Data}

Teknik analisis yang digunakan adalah:

\section{Uji Reliabilitas}

Pada uji reliabilitas dalam penelitian ini digunakan cara one shoot atau pengukuran sekali saja: disini pengukurannya hanya sekali 
kemudian hasilnya dibandingkan dengan pertanyaan lain atau mengukur korelasi antar jawaban pertanyaan. Cronbach Alpha $(\alpha)$ suatu konstruk atau variabel dikatakan reliabel jika memberikan nilai cronbach alpha $(\alpha)>0,70$ (Nunnally dalam Ghozali, 2012)

\section{Analisis Deskriptif}

Analisis ini digunakan untuk mendiskripsikan identitas responden yang terdiri dari nama responden, jenis kelamin, usia, status, intensitas berkunjung, tujuan berkunjung serta items yang didistribusikan dari masing-masing variabel. Setelah data terkumpul, maka selanjutnya adalah pengolahan data, kemudian mendistribusikan kedalam tabel lalu membahas data yang dioleh tersebut secara deskriptif.

\section{Analisis Regresi Linier Berganda}

Penelitian ini menggunakan analisis regresi linier berganda karena ada tiga variabel independen dalam penelitian yaitu Food Quality dan Kesesuaian Harga sedangkan variabel dependennya adalah Kepuasan pelanggan. Menurut Nazir (2014) model analisis Regresi Linier Berganda adalah sebagai berikut: $\mathrm{Y}=\mathrm{a} 0+\mathrm{a} 1 \mathrm{X} 1+\mathrm{a} 2 \mathrm{X} 2$.

\section{Uji t (Uji parsial)}

Uji $\mathrm{t}$ adalah metode dimana kita melihat seberapa besar variabel independen mempengaruhi variabel dipenden.Terdapat 2 cara dalam pengujian $t$ dengan kriteria sebagai berikut:

Jika t hitung $>t$ table maka ho ditolak, sebalik nya jika thitung $<\mathrm{t}$ table maka ho diterima atau mengunakan kriteria lainnya yaitu jika $p<0.05$ maka ho ditolak sebalik nya jika $\mathrm{p}>0.05$ maka ho diterima

\section{Uji F}

Ghazali (2012) Menyebutkan bahwasanya uji Simultan (Uji-F) pada dasarnya menunjukkan apakah semua variable independen yang dimasukan dalam model mempunyai pengaruh secara bersama-sama terhadap variable dependen ataukah tidak.

\section{Koefisien Determinasi}

Menurut Nawari (2010) Koefisen Determinasi digunakan untuk mengukur kemampuan variabel independen dalam menjelaskan variabel dipenden dengan nilai koefisien determinasi menyatakan proporsi keragaman pada variabel bergantung yang mampu dijelaskan oleh variabel penduganya.Banyak peneliti menganjurkan untuk menggunakan nilai Adjusted $\mathrm{R}^{2}$. Tidak seperti nilai $\mathrm{R}^{2}$ nilai adjusted $\mathrm{R}$ dapat naik atau turun apabila satu variabel independent ditambahkan ke dalam model.

\section{HASIL PENELITIAN DAN PEMBAHASAN}

\section{A. Analisis Demografis}

Responden yang digunakan dalam penelitian ini adalah 100 orang konsumen Gaembull Bintaro Sektor 7, baik yang baru pernah mencoba maupun sebagai tamu loyal dari Gaembull. Berdasarkan data demografis responden, didapat data sebagai berikut: Konsumen dengan gender laki-laki lebih banyak dibanding perempuan sebesar $63 \%$ untuk laki-laki dan $37 \%$ untuk perempuan. Selain itu dari sisi usia didominasi oleh kategori usia 20-30 tahun sebanyak 36 orang (36\%), dilanjutkan oleh kategori usia 31-40 tahun sebanyak 32 orang (32\%), 41-50 tahun sebanyak 23 orang $(23 \%),>50$ tahun sebanyak 8 orang $(8 \%)$ dan dibawah $<20$ tahun sebanyak 1 orang (1\%). Dari sisi pekerjaan para konsumen di Gaembull Restoran sendiri didominasi oleh Karyawan yang memiliki jumlah lebih dari setengah responden yaitu sekitar 56 orang (56\%), lalu ada Pengusaha sebanyak 20 orang (20\%), Lainnya diluar kategori sebanyak 17 orang (17\%), dan terakhir 7 orang sebagai Ibu Rumah Tangga. 
Tabel 1. Pendapatan Perbulan

\begin{tabular}{|c|c|c|c|c|c|}
\hline & & Frequency & Percent & Valid Percent & $\begin{array}{c}\text { Cumulative } \\
\text { Percent }\end{array}$ \\
\hline \multirow[t]{5}{*}{ Valid } & > Rp. 5.000.000 - Rp. 8.000.000 & 15 & 15,0 & 15,0 & 15,0 \\
\hline & $\begin{array}{l}\text { > Rp. } 8.000 .000-\text { Rp. } \\
11.000 .000\end{array}$ & 16 & 16,0 & 16,0 & 31,0 \\
\hline & $\begin{array}{l}>\text { Rp. } 11.000 .000 \text { - Rp. } \\
14.000 .000\end{array}$ & 32 & 32,0 & 32,0 & 63,0 \\
\hline & >Rp. 14.000.000 keatas & 37 & 37,0 & 37,0 & 100,0 \\
\hline & Total & 100 & 100,0 & 100,0 & \\
\hline
\end{tabular}

Berdasarkan Pendapatan perbulannya, para konsumen dari Gaembull lebih banyak dari kelas menengah keatas, dimana pendapatan tertinggi para konsumennya didominasi di dua kategori teratas, yaitu kategori $>$ Rp. 11.000 .000 - Rp. 14.000.000 sebanyak 32 orang (32\%) dan >Rp. 14.000 .000 sebanyak 37 orang (37\%). Dimana kebanyakan dari para responden yang diambil untuk penelitian ini kebanyakan dari mereka adalah konsumen yang baru mencoba Restoran ini untuk pertama kalinya. Dimana 57 orang dari mereka baru merasakan sensasi makan "All You Can Eat" di Gaembull dengan paket harga dan kualitas makanan yang ditawarkan sedangkan 43 orang lainnya sudah pernah berkunjung sebelumnya dan merasakan pengalaman makan di restoran tersebut sebelumnya

Tabel 2. Intensitas Berkunjung

\begin{tabular}{crrrrr}
\hline & & & \multicolumn{2}{c}{ Valid } & \multicolumn{2}{c}{$\begin{array}{c}\text { Cumulative } \\
\text { Prequency }\end{array}$} \\
\hline Valid & Percent & Percent & Percent \\
\cline { 2 - 6 } & 1,0 & 57 & 57,0 & 57,0 & 57,0 \\
\cline { 2 - 6 } & 2,0 & 35 & 35,0 & 35,0 & 92,0 \\
\cline { 2 - 6 } & 3,0 & 8 & 8,0 & 8,0 & 100,0 \\
\cline { 2 - 6 } & Total & 100 & 100,0 & 100,0 &
\end{tabular}

Tabel 3. Domisili Berdasarkan Kecamatan daerah Bintaro dan Jakarta

\begin{tabular}{llrrrr}
\hline & & & & \multicolumn{2}{c}{ Cumulative } \\
& & Frequency & Percent & Valid Percent & Percent \\
\hline Valid & 18 & 18,0 & 18,0 & 18,0 \\
\cline { 2 - 6 } & Ciputat & 13 & 13,0 & 13,0 & 31,0 \\
\cline { 2 - 6 } & Ciputat Timur & 5 & 5,0 & 5,0 & 36,0 \\
\cline { 2 - 6 } Jakarta Barat & 10 & 10,0 & 10,0 & 46,0 \\
\cline { 2 - 6 } Jakarta Selatan & 2 & 2,0 & 2,0 & 48,0 \\
\cline { 2 - 6 } Jakarta Utara & 13 & 13,0 & 13,0 & 61,0 \\
\cline { 2 - 6 } & Pamulang & 21 & 21,0 & 21,0 & 82,0 \\
\cline { 2 - 6 } Pondok Aren & 13 & 13,0 & 13,0 & 95,0 \\
\cline { 2 - 6 } Serpong & 5 & 5,0 & 5,0 & 100,0 \\
\cline { 2 - 6 } Serpong Utara & 100 & 100,0 & 100,0 & \\
\cline { 2 - 6 } & Total & & & &
\end{tabular}




\section{B. Hasil Uji Reliabilitas}

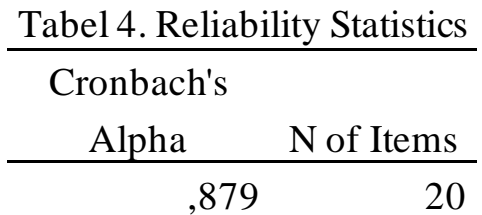

Koefisien reliabilitas butir pernyataan pada kuesioner senilai 0,879, dimananilai tersebut > 0,6.Sesuai dengan teori dari Sugiyono (2017) dapat disimpulkan bahwa seluruh variabel andal (reliable) dalam mengukur variabel nya.

Tabel 5. Coefficients ${ }^{a}$

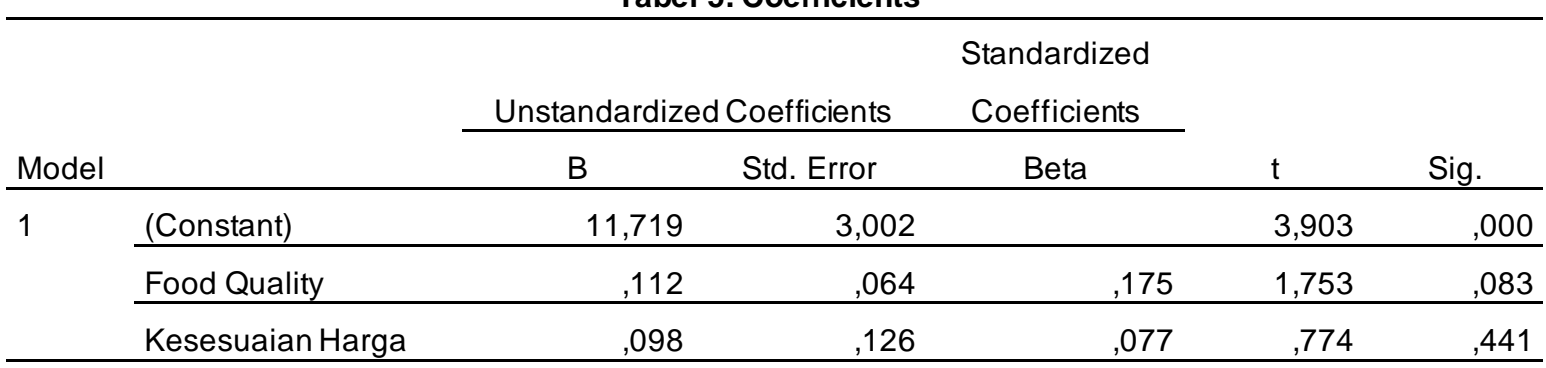

a. Dependent Variable: Kepuasan Konsumen

\section{Hasil Analisis Regresi Berganda}

Untuk persamaan regresi dari variabel diatas didapat nilai sebagai berikut: $\mathrm{Y}=11,719+0,112 \mathrm{X} 1+0.098 \mathrm{X} 2$

\section{Hasil Uji t}

Dari data diatas diperoleh nilai probabilitas signifikan X1 (Food Quality) sebesar 0.083. Dikarenakan nilai probabilitas signifikan X1 > 0.05 maka $\mathrm{H}_{\mathrm{o}}$ diterima dan $\mathrm{H}_{1}$ ditolak, dapat disimpulkan bahwa variabel independen (X1) tidak berpengaruh secara signifikan terhadap variabel dependen (Y). Kemungkinan Food Quality tidak berpengaruh terhadap Kepuasan Konsumen dapat dipengaruhi oleh banyak hal dalam menilai kualitas sebuah makanan, seperti yang telah disebutkan sebelumnyaoleh Widjaja (2006) beberapa faktor yang mempengaruhi pendapat masing-masing orang tentang kriteria tersebut antara lain usia, latar belakang budaya dan sosial, ekonomi, pengalaman masa lalu yang berkaitan dengan makanan, pendidikan dan pengetahuan ilmiah serta emosi. Sehingga hasil dari kualitas makanan sendiri walau telah memiliki standar yang sama antar penyajian kepada para konsumen dapat menghasilkan persepsi dan penilaian yang berbeda akibat faktor-faktor tersebut. Dan untuk X2 (Kesesuaian Harga) sama dengan X1, dimana nilai probabilitas signifikannya sebesar 0,441 sehingga $\mathrm{H}_{\mathrm{o}}$ diterima dan $\mathrm{H}_{1}$ ditolak. Oleh karena itu dengannilai tersebut dinyatakan juga bahwa secara partial Kesesuain Harga (X2) tidak berpengaruh secara signifikan terhadap Kepuasan Konsumen di Gaembull Restaurant. Didukung dengan memang tingginya pendapatan para konsumen yang datang ke Gaembull merupakan suatu catatan bagi pihak restoran untuk mengkategorikan segment market konsumen mereka untuk kedepannya. Dimana para konsumennya datang untuk makan disana tidak hanya karena harga yang mereka anggap sesuai untuk makanan yang telah disajikan, tetapi bisa jadi karena faktor lainnya seperti lokasi, atmosphere, maupun marketing yang digunakan oleh pihak restoran. 


\section{E. HASIL UJI F}

Tabel 6. ANOVAa

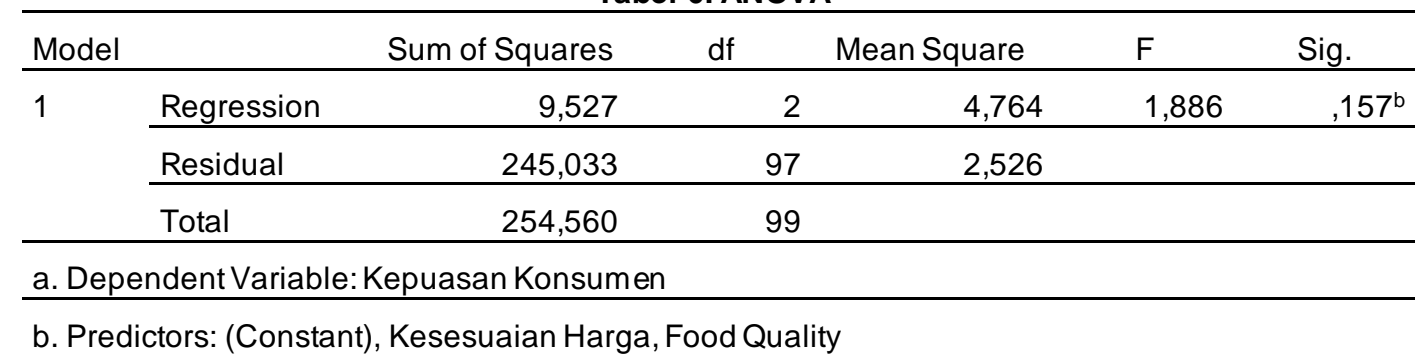

Berdasarkan hasil uji Anova diatas, diperoleh nilai Fhitung adalah 1,886 dengan tingkat signifikansi 0,157. Karena Fhitung < Ftabel maka H0 ditolak. Pengambilan keputusan juga dapat dilakukan dengan melihat probabilitasnya dimana nilai $0.157>0.05$ sehingga $\mathrm{H} 0$ diterima. Artinya secara simultan kedua variabel yaitu Kesesuaian Harga dan Food Quality tidak berpengaruh terhadap Kepuasan Konsumen

\section{F. HASIL UJI KOEFISEN DETERMINASI}

Tabel 7. Model Summary

\begin{tabular}{llccc}
\hline Model & R & R Square & $\begin{array}{c}\text { Adjusted R } \\
\text { Square }\end{array}$ & $\begin{array}{c}\text { Std. Error of } \\
\text { the Estimate }\end{array}$ \\
\hline 1 &, $193 a$ &, 037 &, 018 & 1,5894 \\
\hline a. Predictors: (Constant), Kesesuaian Harga, Food Quality
\end{tabular}

Dari hasil pengolahan tersebut diperoleh koefisien determinasi diperoleh (Adjusted $\mathrm{R}$ Square) sebesar 0,018 atau dengan nilai persen sebesar 1,8\%. Dimana pengaruh dari Food Quality dan Kesesuaian Harga hanya sebesar $1,8 \%$ terhadap Kepuasan Konsumen. Sehingga menjadi acuan bahwa, banyak faktor lainnya selain kedua faktor tersebut yang sangat mempengaruhi Kepuasan Konsumen sebanyak 98,2\% lainnya. Penelitian ini merupakan pembuktian bahwa harga tidak menjadi faktor utama untuk dapat memuaskan seseorang saat memilih restoran "All You Can Eat" seperti yang telah di lakukan oleh Wei (2003), dimana nilai tertinggi didapat dari Harga yang ditawarkan, variasi makanan dan layanan yang ditawarkan.

\section{SIMPULAN}

Berdasarkan hasil perhitungan dan analisis sebelumnya, dapat disimpulkan bahwa:

1. Konsumen pria lebih mendominasi sebesar 63\%, dimana konsumen terbanyak datang dari kategori usia 20-30 tahun sebanyak 36 orang $(36 \%)$, dengan tipe pekerjaaan karyawan 56 orang. Selain itu ratarata pendapatan konsumen terbanyak dari kalanagan menengah keatas dengan pendapatan diatas Rp. 14.000.000 sebanyak 37 orang dan berasal dari daerah Pondok Aren yang merupakan bagian dari Kecamatan di Bintaro yang berjarak sekitar $1.5 \mathrm{~km}$ dari lokasi Gaembull Restaurant sendiri

2. Tidak ada pengaruh secara partial dan simultan dari Food Quality dan Kesesuaian Harga terhadap Kepuasan Konsumen di Gaembull Restoran Bintaro Sektor 7. Hal ini mengindikasikan bahwa para konsumen mungkin puas tidak diukur hanya dari Kualitas makanan yang disajikan juga harga yang ditawarkan. Hal tersebut didukung bahwa Food Quality dan Kesesuaian Harga hanya bernilai $1,8 \%$ dari keseluruhan faktor 
untuk Kepuasan Konsumen di Gaembull Restoran.Peneliti lain dapat melihat faktor lainnya seperti lokasi, atmosphere ataupun fasilitas lainnya yang telah dimiliki oleh Gaembull Restoran ini.

Penelitian ini merupakan pembuktian dari beberapa penelitian sebelumnya bahwa faktor harga dan kualitas makanan tidak menjadi faktor terbesar bagi konsumen untuk dapat menikmati atau puas dengan restoran "All You Can Eat"

\section{DAFTAR PUSTAKA}

\section{Buku}

Ghozali, I. 2012. Aplikasi Analisis Multivariate dengan Program IBM SPSS. Yogyakarta: Universitas Diponegoro.

Kotler, P. dan Armstrong, G. 2008. Prinsipprinsip Pemasaran. Jilid 1. Jakarta: Erlangga.

of Marketing 14th Edition. New

Jearsey: Pearson Education Inc

Mertayasa, I Gede A. 2012. Food and

Beverage Service Operational. Yogyakarta: Andi.

Nawari. 2010. Analisis Regresi dengan Ms

Excel 2017 dan SPSS 17. Jakarta:

Gava Media.

Nazir, Moh. 2014. Metode Penelitian. Bogor:

Penerbit Ghalia Indonesia

Setiyadi, N. J. 2010. Perilaku Konsumen.

Jakarta: Kencana Prenada Media

Sugiyono. 2010. Metodologi Penelitian

Administrasi .Bandung: Alfabeta.

Sugiyono. 2017. Metode Penelitian

Pendidikan Pendekatan Kuantitatif.

Bandung: Alfabeta.

Sunyoto, Danang. 2013. Teori, Kuesioner dan

Analisis Data. Yogyakarta: Graha

Ilmu.

Tjiptono, Fandy. 2004. Perspektif Manajemen

dan Pemasaran Kontemporer.

Yogyakarta: Andi.

Umar, Husain. 2005. Manajemen Riset dan

Perilaku Konsumen. Jakarta: PT.

Gramedia Pusat

\section{Jurnal}

Hanaysha, Jalal. 2016. Testing The Effect of Food Quality, Price Fairness and Physical Environment On Customer
Satisfaction In Fast Food Restaurant

Industry. Asian Economic and Social

Society, Vol.6, pp. 31-40.

Warisan, Johan dan Harianto, Agung.2018.

Faktor yang mempengaruhi

Keputusan Konsumen Dalam

Memilih Restoran All You Can Eat di

Surabaya. Jurnal Hospitality dan

Manajemen Jasa. Vol 6 No. 1. Hal 40-53

Wei, C. T. 2003. A Customer and Satisfaction Survey for A Chinese Buffet. Wisconsin: University of Wisconsin-Stout.Widjaya, S. 2006. Analisa Harapan dan Persepsi Penumpang Terhadap Kualitas Makanan yang Disediakan Oleh Maskapai Penerbangan Domestik di Indonesia. Jurnal Manajemen Perhotelan. 2(1), 36-46.

Website

Alika, Rizky.

https://katadata.co.id/berita/2019/1

1/12/daya-beli-melemah-

pertumbuhan-industri-makananterkoreksi

https://pergikuliner.com/

Juniman, P. T. (2017, januari 18). CNN Indonesia. Diambil kembali dari https://www.cnnindonesia.com/ga ya-hidup

Mayounga, A. T. (2018) "Antecedents of recalls prevention: analysis and synthesis of research on product recalls." Supply Chain Forum: An International Journal, 19(3). 